\title{
Factors associated with medical students' self-regulated learning and its relationship with clinical performance: a cross-sectional study
}

\author{
Jia-Yu Zhang ${ }^{1,2}$, Yi-Juan Liu², Tao Shu ${ }^{2}$, Ming Xiang ${ }^{2 *}$ and Zhan-Chun Feng ${ }^{1 *}$
}

\begin{abstract}
Background: The importance of self-regulated learning (SRL) has been broadly recognised by medical education institutions and medical professionals. Self-regulated learning, which is a context-specific process, is affected by personal, contextual and social factors. Although many studies on exploring the factors that influenced SRL and the relationship of between SRL and clinical achievement levels have been carried out in western countries, little is known about the factors associated with self-regulated learning and its relationship with clinical performance among medical students in China.
\end{abstract}

Methods: A cross-sectional online survey was distributed to 3rd year clinical medicine students who were in the clinical clerkship stage in a medical college in Wuhan. We used Self-regulated Learning Scale for Undergraduates (SLSU) to measure the self-regulated learning of students and Objective Structured Clinical Examination (OSCE) in the national proficiency test to assess the clinical performance of students. The participation rate was 73.95\% (193 students). An independent t-test and analysis of variance were used to analyse the factors associated with self-regulated learning. The relationship between self-regulated learning and clinical performance was analysed with multilinear regression analysis.

Results: Univariate analysis showed that having a clear career planning and a professional idol, providing full-time teaching clinical teachers in the clerkship department and seeking the help of the surrounding classmates and the guidance of teachers or senior students were significant predictors of self-regulated learning. Multilinear regression analysis has revealed a positive relationship among extrinsic goals (partial $r=0.171$ ), clinical clerkship evaluation (partial $r=0.197)$ and clinical performance $(F=4.070, p=0.004)$.

Conclusions: Motivation-related personal and social factors related to clinical context could promote the SRL level of medical students in China. Extrinsic goals and clinical clerkship evaluation could facilitate students' clinical achievements on clinical skills. External support, such as clinical clerkship management, might improve clinical performance on clinical skills in clinical clerkship context.

\footnotetext{
*Correspondence: xiangming@mails.tjmu.edu.cn; zcfeng@hust.edu.cn

${ }^{1}$ School of Medicine and Health Mangement, Tongji Medical College,

Huazhong University of Science and Technology, No. 13 Hangkong Road,

Qiaokou Region, Wuhan City, Hubei Province, China

${ }^{2}$ Medical academic affairs office, Tongji Medical College, Huazhong

University of Science and Technology, Wuhan, China
}

(c) The Author(s) 2022. Open Access This article is licensed under a Creative Commons Attribution 4.0 International License, which permits use, sharing, adaptation, distribution and reproduction in any medium or format, as long as you give appropriate credit to the original author(s) and the source, provide a link to the Creative Commons licence, and indicate if changes were made. The images or other third party material in this article are included in the article's Creative Commons licence, unless indicated otherwise in a credit line to the material. If material is not included in the article's Creative Commons licence and your intended use is not permitted by statutory regulation or exceeds the permitted use, you will need to obtain permission directly from the copyright holder. To view a copy of this licence, visit http://creativecommons.org/licenses/by/4.0/. The Creative Commons Public Domain Dedication waiver (http://creativeco mmons.org/publicdomain/zero/1.0/) applies to the data made available in this article, unless otherwise stated in a credit line to the data. 
Keywords: Self-regulated learning, Clinical skill, Clinical performance, Medical education

\section{Background}

Self-regulated learning is the process of being metacognitive, motivational and behavioural proactive in the learning process according to the theoretical model of Zimmerman [1]. This model consists of three phases: forethought, performance and self-reflection phases. More specifically, self-regulated learners effectively set goals; plan and use strategies to achieve their goals; manage their resources in the forethought phase; seek to manage emotions, cognition and behaviour to attain their forethought goals in the performance phase; selfevaluate whether they have attained their goals and modify or adapt their goals or strategies for future learning in the self-reflection phase [2, 3].

Self-regulation is a complex interactive process of physical and mental activities, which are affected by personal, social and contextual attributes [2, 4, 5]. Personal and social attributes are closely related to its three-phases process [6]. Studies have shown that goals have a motivational function on SRL $[7,8]$. The use of goal setting and learning plans allow for adaptation to person and context in the forethought phases. Personal attributes found to affect SRL on a more general level of students in China included grade and major $[9,10]$. In addition to these factors, studies showed that financial status and clinical internship experience could affect SRL in medical students, to name a few $[11,12]$. The support of a coach or mentor might be a prerequisite for the SRL process to develop to its full potential in the performance phases. Social attributes affecting SRL of paediatric residents in North American countries pertained to the influence of supervisor and peers [13], faculty staff support [14], among others. Contextual attributes known to affect self-regulation of medical students in a classroom setting in European or North American countries included available facilities and curriculum pedagogy, among others [15-17].

One of the important factors contributing to enhance students' academic performance was self-regulated learning. Self-regulated students were more effective learners who attained higher grades during high school and in non-medical college [18-20]. Besides, many studies have adopted different research methods to demonstrate this positive relationship in medical students [21-23]. Students who were successful in venipuncture had strong high levels of strategic thinking using SRL microanalysis, which was a tool to examine the self-regulatory profiles of successful performers and strugglers across three phases [3]. In addition, positive relations of monitoring, reflection and effort with firstyear GPA of students were found using the Self-Regulation of Learning Self-Report Scale [23]. Furthermore, correlation analysis showed significant association of autonomous motivation with higher levels of academic achievement using the Academic Motivation Scale [21]. OSCE scores of the students were observed to increase in conjunction with increased self-efficacy levels using Motivated Strategies for Learning Questionnaire [22].

Self-regulated learning is an important strategy for the continuous professional development of medical students [24]. Many studies on exploring the factors influencing SRL and the relationship of SRL and achievement levels have been carried out. However, to our knowledge, research on SRL of medical students in China during clinical clerkship is largely lacking. Moreover, no research has explored the relationship between SRL and clinical performance in Chinese medical students. Considering the huge difference between clinical medical education in western countries and China, carrying out research on SRL was necessary in the domestic clinical context. Besides, family economy and family culture, which might be potential confounding factors, could improve students' academic performance according to the family capital theory. Therefore, we included family economy variables such as area of residence and household income and family culture variables such as parents' educational level and parents' expectations into this study [25]. This study focused on the factors associated with self-regulated learning and its relationship with clinical skills during their clinical clerkship. The following questions were put forth:

1. What factors affect medical students' self-regulated learning in their clinical clerkship?

2. Is there a relationship between the self-regulated learning ability of medical students and clinical performance in the clinical clerkship?

\section{Method}

\section{Setting}

We conducted a cross-sectional survey among students enrolled in different clerkships at the beginning of the rotational stage. The target population consisted of medical students majoring in Clinical Medicine (5-year schooling) at the Tongji Medical College Huazhong University of Science and Technology, China. The clinical medicine project, which adopts traditional and PBL 
teaching methods, includes a pre-clinical phase (Years 1-2.5) and a clinical phase (Years 2.5-5). The clinical phase consists of rotational clerkships ranging from 2 weeks to 16 weeks in duration. The electronic survey, which was anonymous and confidential, was distributed electronically by WeChat tools to 261 students in the clinical clerkship stage on June 2021 with the Wenjuanxing platform.

\section{Data collection}

The study participants were 3rd year medical students, and 193 students completed the questionnaire $(73.95 \%$ response rate). Among these 193 students, 150 (77.72\%) have correctly filled in their student ID. Therefore, we could obtain their clinical skill scores and age according to their student ID. To maximise the use of data, all analyses except samples with incorrect student IDs when it came to the analysis of clinical skill scores, were regarded as valid samples. The male/female ratio was approximately 1:1 (Male: 97, Female: 96) and the mean age was $22.3 \pm 0.88$. The study was approved by the institutional review boards of the Tongji Medical College Huazhong University of Science and Technology.

\section{Instruments}

\section{Self-regulated learning scale for undergraduates}

SLSU was developed by Chinese researchers on the basis of Zimmerman's self-regulated learning theory according to the actual situation of college students in China [26]. This scale was divided into two subscales: the learning motivation scale (LMS) and the learning strategy scale (LSS). Items were scored on a 5-point Likert scale ranging from one (totally disagree) to five (totally agree). Additionally, the expressions of some items were modified according to the characteristics of clinical clerkship (e.g. changing the following 'I often found pleasure in the study' to 'I often found pleasure in clinical clerkship'). A total of 7 items (e.g. 'I arrange the time to do the most important thing first') were deleted because of its inapplicability in the clinical setting.

LMS was made up of 25 items covering five domains of learning motivation: self-efficacy (six items), intrinsic goals (eight items), control beliefs about learning (seven items), extrinsic goals (two items) and clinical clerkship value (two items). LSS was made up of 37 items covering three domains of learning strategy: test anxiety (four items), general method (five items), help seeking during clinical clerkship (eight items), study plan during clinical clerkship (six items), clinical clerkship summary (five items), clinical clerkship evaluation (three items) and clinical clerkship management (four items). The reliability of the subdimensions for the motivation dimension ranged between 0.74 and 0.97 , whilst this value ranged between 0.74 and 0.93 for the learning strategies dimension (Table 1).

\section{Clinical performance}

The clinical skill test, which was evaluated by the Objective Structured Clinical Examination in the national proficiency test, was used to assess clinical performance of the students. The OSCE includes 6 stations included in taking patient history (Stations I and II), physical examination skills (Stations III and IV) and basic clinical skills (Stations V and VI).

Table 1 The mean of SLSU scores of students and the Cronbacha coefficient of SLSU

\begin{tabular}{|c|c|c|c|c|}
\hline Scale & Items & Mean & SD & Alpha \\
\hline Self-regulated learning & & 3.53 & 0.60 & 0.98 \\
\hline \multirow[t]{6}{*}{ Learning motivation } & & 3.53 & 0.64 & 0.97 \\
\hline & Self-efficacy & 3.39 & 0.83 & 0.92 \\
\hline & Intrinsic goals & 3.78 & 0.81 & 0.95 \\
\hline & Control beliefs about learning & 3.65 & 0.72 & 0.92 \\
\hline & Extrinsic goals & 3.05 & 0.95 & 0.74 \\
\hline & Clinical clerkship value & 3.76 & 0.92 & 0.94 \\
\hline \multirow[t]{8}{*}{ Learning strategy } & & 3.52 & 0.60 & 0.96 \\
\hline & Test anxiety & 3.58 & 0.84 & 0.91 \\
\hline & General method & 3.70 & 0.73 & 0.92 \\
\hline & Help seeking during clinical clerkship & 3.49 & 0.75 & 0.93 \\
\hline & Study plan during clinical clerkship & 3.42 & 0.80 & 0.93 \\
\hline & Clinical clerkship summary & 3.36 & 0.81 & 0.93 \\
\hline & Clinical clerkship evaluation & 3.50 & 0.80 & 0.85 \\
\hline & Clinical clerkship management & 3.64 & 0.80 & 0.74 \\
\hline
\end{tabular}




\section{Statistical analysis}

Statistical analyses were performed with SPSS for Windows version 21 and the statistical computing language $R$ [27]. Categorical variables were presented as numbers and percentages and continuous variables as mean \pm standard deviation (SD). Continuous variables with Student's t-tests or analysis of variance. Multivariate linear regression analysis was conducted to evaluate the association between self-regulated learning and clinical performance. The assumptions of the multilinear regression analysis were investigated before performing the analysis. Variance inflation factor (VIF) was used to examine the multicollinearity of the regression analysis. Durbin-Watson (DW) autocorrelation statistic was generated to identify models with serial autocorrelation. A value of VIF higher than 10 was considered to be a multicollinearity, and a value of DW between 1.5 and 2.5 was considered to have no autocorrelation [28]. A $p$-value of 0.05 (two-tailed) was considered to be statistically significant. In this study, the values of VIF (1.248-7.226) and DW (1.837) were both in the allowable range.

\section{Results}

\section{Descriptive statistics of personal characteristics and environmental factors}

Out of the 261 students who were invited to participate, 193 responses were received giving an overall response rate of $73.95 \%$. The mean scores ranged between 3.05 and 3.78 in the LMS section and between 3.36 and 3.64 in the LSS section. The overall mean score and reliability coefficient of the SLSU were 3.49 and 0.98 , respectively (Table 1). The numbers (percentages) of municipalities or provincial capitals, prefecture-level cities, countylevel cities and town or rural areas were 39 (20.2\%), 56 (29\%), 53 (27.5\%) and 45 (23.3\%), respectively. Over fourfifths $(84.4 \%)$ of the students' family income were below 200,000 (CNY). Approximately 90 respondents had a professional idol and a clear career planning. A total of 77 students have encountered a full-time teaching clinical teacher in the current clerkship department. Approximately 170 students sought the help of their surrounding classmates and the guidance of teachers or senior students. Additionally, 112 students experienced medical disputes during their clinical clerkship (Additional file 1).

\section{Analysis of differences in SRL according to personal characteristics and environmental factors}

Table 2 displays the differences in the means and standard deviations of self-regulated learning and its subscales among individual and environmental feature groups. Among these factors, a professional idol $(p=0.029)$, a clear career planning $(p=0.001)$, full-time clinical teaching teachers $(p=0.041)$, the help of surrounding classmates $(p<0.001)$ and the guidance of teachers or senior students $(p<0.001)$ had a univariate correlation with the self-regulated learning ability. However, no differences existed in personal characteristics, such as gender, area of residence, among others. This study also analysed the relationships between these variables and learning motivation and learning strategy. Table 2 displays the detailed statistical results.

\section{Relationship between self-regulated learning and clinical performance}

We used the method of backward stepwise regression to screen variables that had an impact on the level of students' clinical skills. The subdimensions of learning motivations and learning strategies indicated a weak but meaningful relationship with the OSCE scores $(\mathrm{F}=4.070$, $p=0.004 ; \quad R^{2}=0.098, \quad$ Adjust- $\left.R^{2}=0.074\right) \quad($ Table 3$)$. According to the standardised regression coefficients, the most important subdimensions relative to OSCE score were clinical clerkship evaluation and extrinsic goals.

Clinical clerkship evaluation and extrinsic goals were positively correlated $(r=0.197, r=0.171)$ with OSCE scores at the statistical level of 0.05 . Clinical clerkship management was positively correlated $(r=0.153)$ with OSCE scores, whilst control over learning beliefs were negatively correlated $(r=-0.159)$ with OSCE scores at the statistical level of 0.1 .

\section{Discussion}

By exploring factors that influenced medical students' self-regulated learning in clinical setting, our study revealed that motivation-related personal factors and social factors related to clinical context could promote the SRL level of students. Learning motivation (extrinsic goals) and learning strategy (clinical clerkship evaluation) were positively associated with students' clinical achievements on clinical skills. External support, such as clinical clerkship management, might improve clinical skills in clinical setting.

\section{What factors influence the self-regulated learning levels of medical students during clinical clerkship?}

Most of the factors associated with self-regulated competence were motivation-related factors. Students with a clear career plan and have a professional idol had a higher level of SRL. This result supported the arguments of Zimmerman theory, which suggested that self-motivation beliefs such as self-efficacy and goal orientation provide the impetus or motivation for a learner to put forth the necessary effort to engage in the self-regulation process [29]. A clear career plan and with professional idols might improve students' self-efficacy, thereby enhancing 
Table 2 Differences in self-regulated learning and its subscales by personal characteristics and environmental factors

\begin{tabular}{|c|c|c|c|c|c|c|c|}
\hline \multirow[t]{2}{*}{ Variables } & \multirow[t]{2}{*}{ Items } & \multicolumn{2}{|l|}{$\begin{array}{l}\text { Learning } \\
\text { motivation }\end{array}$} & \multicolumn{2}{|c|}{ Learning strategy } & \multicolumn{2}{|c|}{$\begin{array}{l}\text { Self-regulated } \\
\text { learning }\end{array}$} \\
\hline & & Mean \pm SD & $p$ & Mean \pm SD & $p$ & Mean \pm SD & $p$ \\
\hline \multirow[t]{2}{*}{ Gender } & Male & $3.50 \pm 0.73$ & 0.420 & $3.53 \pm 0.67$ & 0.711 & $3.52 \pm 0.67$ & 0.805 \\
\hline & Female & $3.57 \pm 0.54$ & & $3.50 \pm 0.53$ & & $3.54 \pm 0.52$ & \\
\hline \multirow[t]{4}{*}{ Area of residence } & Municipalities/Provincial capitals & $3.54 \pm 0.63$ & 0.514 & $3.53 \pm 0.58$ & 0.532 & $3.53 \pm 0.58$ & 0.490 \\
\hline & Prefecture-level city & $3.63 \pm 0.67$ & & $3.59 \pm 0.63$ & & $3.61 \pm 0.63$ & \\
\hline & County-level cities & $3.44 \pm 0.73$ & & $3.42 \pm 0.64$ & & $3.43 \pm 0.66$ & \\
\hline & Town/Rural areas & $3.52 \pm 0.50$ & & $3.52 \pm 0.53$ & & $3.52 \pm 0.49$ & \\
\hline \multirow[t]{7}{*}{ Parents' highest education level } & Elementary School & $3.45 \pm 1.02$ & 0.863 & $3.37 \pm 0.8$ & 0.721 & $3.41 \pm 0.9$ & 0.810 \\
\hline & Junior High School & $3.54 \pm 0.65$ & & $3.52 \pm 0.62$ & & $3.53 \pm 0.61$ & \\
\hline & Senior High School & $3.45 \pm 0.37$ & & $3.44 \pm 0.40$ & & $3.45 \pm 0.37$ & \\
\hline & $\begin{array}{l}\text { Technical Secondary School/Junior } \\
\text { College }\end{array}$ & $3.53 \pm 0.74$ & & $3.61 \pm 0.69$ & & $3.57 \pm 0.69$ & \\
\hline & Undergraduate & $3.54 \pm 0.60$ & & $3.48 \pm 0.6$ & & $3.51 \pm 0.56$ & \\
\hline & Master & $3.75 \pm 0.35$ & & $3.67 \pm 0.31$ & & $3.71 \pm 0.33$ & \\
\hline & Doctor & $3.84 \pm 0.29$ & & $3.79 \pm 0.24$ & & $3.81 \pm 0.24$ & \\
\hline \multirow[t]{3}{*}{ Parents' expectations of your education } & Undergraduate & $3.46 \pm 1.01$ & 0.769 & $3.46 \pm 0.8$ & 0.420 & $3.46 \pm 0.89$ & 0.586 \\
\hline & Master & $3.50 \pm 0.50$ & & $3.45 \pm 0.49$ & & $3.48 \pm 0.48$ & \\
\hline & Doctor & $3.56 \pm 0.67$ & & $3.57 \pm 0.63$ & & $3.56 \pm 0.62$ & \\
\hline \multirow{5}{*}{$\begin{array}{l}\text { Average annual household income } \\
\text { (CNY) }\end{array}$} & 50,000 and bellow & $3.44 \pm 0.76$ & 0.629 & $3.44 \pm 0.68$ & 0.461 & $3.44 \pm 0.7$ & 0.529 \\
\hline & $50,000-100,000$ & $3.52 \pm 0.63$ & & $3.47 \pm 0.55$ & & $3.49 \pm 0.57$ & \\
\hline & $100,000-200,000$ & $3.62 \pm 0.56$ & & $3.59 \pm 0.63$ & & $3.61 \pm 0.56$ & \\
\hline & $200,000-400,000$ & $3.62 \pm 0.50$ & & $3.68 \pm 0.53$ & & $3.65 \pm 0.48$ & \\
\hline & 400,000 and above & $3.50 \pm 0.77$ & & $3.50 \pm 0.48$ & & $3.5 \pm 0.61$ & \\
\hline \multirow[t]{2}{*}{ Whether to have a professional idol } & Yes & $3.63 \pm 0.66$ & 0.063 & $3.63 \pm 0.59$ & 0.019 & $3.63 \pm 0.61$ & 0.029 \\
\hline & No & $3.45 \pm 0.61$ & & $3.42 \pm 0.59$ & & $3.44 \pm 0.58$ & \\
\hline \multirow{2}{*}{$\begin{array}{l}\text { Whether to have a clear career plan- } \\
\text { ning }\end{array}$} & Yes & $3.67 \pm 0.71$ & 0.005 & $3.68 \pm 0.66$ & 0.001 & $3.68 \pm 0.66$ & 0.001 \\
\hline & No & $3.42 \pm 0.56$ & & $3.38 \pm 0.50$ & & $3.4 \pm 0.51$ & \\
\hline \multirow{2}{*}{$\begin{array}{l}\text { Whether to have full-time teaching } \\
\text { clinical teachers in the current clerkship } \\
\text { department }\end{array}$} & Yes & $3.67 \pm 0.60$ & 0.018 & $3.61 \pm 0.61$ & 0.072 & $3.64 \pm 0.58$ & 0.029 \\
\hline & No & $3.45 \pm 0.65$ & & $3.45 \pm 0.59$ & & $3.45 \pm 0.6$ & \\
\hline \multirow{2}{*}{$\begin{array}{l}\text { Whether to seek the help of the sur- } \\
\text { rounding classmates }\end{array}$} & Yes & $3.62 \pm 0.57$ & $<0.001$ & $3.61 \pm 0.56$ & $<0.001$ & $3.61 \pm 0.54$ & $<0.001$ \\
\hline & No & $2.99 \pm 0.83$ & & $2.91 \pm 0.50$ & & $2.95 \pm 0.64$ & \\
\hline \multirow{2}{*}{$\begin{array}{l}\text { Whether to seek the guidance of teach- } \\
\text { ers or senior students }\end{array}$} & Yes & $3.61 \pm 0.58$ & $<0.001$ & $3.58 \pm 0.58$ & $<0.001$ & $3.59 \pm 0.55$ & $<0.001$ \\
\hline & No & $2.92 \pm 0.82$ & & $2.97 \pm 0.55$ & & $2.94 \pm 0.67$ & \\
\hline \multirow{2}{*}{$\begin{array}{l}\text { Whether to experience medical dispute } \\
\text { during clinical clerkship }\end{array}$} & Yes & $3.56 \pm 0.65$ & 0.514 & $3.54 \pm 0.59$ & 0.534 & $3.55 \pm 0.60$ & 0.507 \\
\hline & No & $3.5 \pm 0.63$ & & $3.49 \pm 0.62$ & & $3.49 \pm 0.60$ & \\
\hline
\end{tabular}

Statistically significant values are indicated in bold

Table 3 The Multiple Liner Regression Analysis Results for Students' Objective Structured Clinical Exam Score

\begin{tabular}{|c|c|c|c|c|c|c|c|c|}
\hline \multirow[t]{2}{*}{ Items } & \multirow[t]{2}{*}{ B } & \multirow[t]{2}{*}{ SE } & \multirow[t]{2}{*}{ b } & \multirow[t]{2}{*}{$\mathbf{t}$} & \multirow[t]{2}{*}{$p$} & \multicolumn{2}{|l|}{$95 \% \mathrm{Cl}$} & \multirow[t]{2}{*}{ Partial $r$} \\
\hline & & & & & & lower & upper & \\
\hline Constant & 73.046 & 3.393 & & 21.528 & $<0.001$ & 66.342 & 79.751 & \\
\hline Control beliefs about learning & -1.998 & 1.015 & -0.221 & -1.968 & 0.051 & -4.005 & 0.008 & -0.159 \\
\hline Extrinsic goals & 1.223 & 0.575 & 0.191 & 2.125 & 0.035 & 0.086 & 2.360 & 0.171 \\
\hline Clinical clerkship evaluation & 2.223 & 0.904 & 0.280 & 2.46 & 0.015 & 0.437 & 4.009 & 0.197 \\
\hline Clinical clerkship management & 1.159 & 0.612 & 0.156 & 1.893 & 0.060 & -0.051 & 2.369 & 0.153 \\
\hline
\end{tabular}

Statistically significant values are indicated in bold, $\mathrm{F}=4.070, p=0.004 ; R^{2}=0.098$, Adjust $-R^{2}=0.074$ 
their independent learning in the process of clinical practice. This finding was in line with previous reports of SRL in other settings, which stated that goals could function as regulatory agents for SRL [8].

Earlier research on SRL in classroom settings have proven that direct instruction by teachers or opportunities for modelling these strategies by senior students could support SRL [30, 31]. Our research results, conducted in the clinical settings, were consistent with those found in the classroom settings. Social-cognitive models of self-regulation suggest that individuals are active participants who seek control over important events through the regulation of their thoughts and actions to achieve personal goals in the performance phase [32]. The possible reason could be that peer-assisted learning was considered to ease the learning process and mobilise students' initiative in learning [33].

Although many medical undergraduate learners naturally exhibit adaptive self-regulation processes, one or more of these processes may be under developed in any given student, and most students do not fully develop the competency they require to adequately self-regulate their learning independently [3, 7]. Students who have experienced a clerkship in a department with a full-time instructor had strong SRL ability. Full-time tutors could devote extra time and energy to guide students. They might also be more familiar with the strategy of SRL. Therefore, they were conducive to the improvement of students' SRL ability, especially for those students with a large number of deficiencies.

\section{Is there a relationship between medical students' self-regulated learning competence and clinical skills in the clinical clerkship?}

The relation between self-regulated learning skills and academic performance is limited [23]. The theoretical model of Zimmerman regarded goals as a critical element in the self-regulation process. Intrinsic goal orientation for learning was correlated with the higher levels of performance conducted in the classroom setting [34-36]. We found that extrinsic goals were correlated with the higher levels of OSCE in clinical clerkship. In addition, the results showed that clinical management had an impact on clinical performance. These findings might be caused by the time conflict between clinical clerkship and postgraduate entrance examinations in the domestic medical education system. A majority of students were more likely to prepare for the examination to obtain better career development prospects during their clerkship stage. This scenario led to a lower sense of self-efficacy for clinical clerkship compared with postgraduate entrance examinations in medical students. Although self-efficacy was a key component in the learning forethought process according to Zimmerman theory, the external support such as clinical clerkship management and the extrinsic goals such as grades ranking might be important for learning clinical skills in China [1].

Results showed that a weak negative correlation exists between control beliefs about learning and OSCE score but did not reach statistical significance. Interestingly, this phenomenon was also found in another study that reported the partial $r$ of -0.17 conducted in surgical clerkship in Turkey [22]. The attainment of clinical skills is difficult to accomplish by one person and must therefore be done in cooperation. Students need support such as an experienced tutor to improve their clinical skills in the clinical environment. The conclusion that additional external support was needed in learning the clinical skills during clinical clerkship was also found in the analysis of learning strategy. Learning strategy such as clinical clerkship evaluation could promote the improvement of clinical skills. Greater use of learning strategies such as elaboration and critical thinking were associated with higher levels of performance in a medical gross anatomy course [34]. Students could rely on elaboration and critical thinking to improve academic performance in theoretical courses. However, additional external support, especially in China, might be needed to improve clinical skills in the clinical practice process.

\section{Limitations}

The study currently contains some limitations. First is the response bias due to the small sample size, which might have caused the sampling to miss the students who are poor at self-regulation and whose motivation to respond to the online questionnaire was low. Secondly, no standardised scale exists for measuring students' self-regulated learning ability. The scale which was widely used in China for investigation might compensate for the obstacles compared with peers worldwide. Moreover, owing to the single institution design of the study, care must be taken not to overinterpret our findings, particularly with respect to transitions in other medical schools and countries. Furthermore, although personal characteristics such as age were not gathered in the survey, age were obtained according to their student ID and had no impact on clinical performance. In the end, the unbalanced personal characteristics (e.g. whether to seek the help of the surrounding classmates and whether to seek the guidance of teachers or senior students) data and the unknown prior achievement level may adversely affect the results. 


\section{Conclusion}

The findings obtained from this study showed that motivation-related personal factors (clear career planning and professional idol) and social factors (full-time teaching clinical teachers, the help of the surrounding classmates and the guidance of teachers or senior students) were significant predictors of self-regulated learning. Additionally, a positive relationship exists between extrinsic goals and clinical clerkship evaluation and clinical performance. Further research is also needed to identify the effect of external support on clinical academic performance in clinical setting. Considering that self-regulated learning in the clinical environment is a complex process that results from an interaction between person and context, further investigation on risk factors is necessary in the clinical environment of self-regulated learning.

\section{Abbreviations}

SRL: Self-regulated Learning; SLSU: Self-regulated Learning Scale for Undergraduates; OSCE: Objective Structured Clinical Examination; LMS: Learning Motivation Scale; LSS: Learning Strategy Scale; SD: Standard deviation; VIF: Variance inflation factor; DW: Durbin-Watson; MSLQ: Motivated Strategies for Learning Questionnaire.

\section{Supplementary Information}

The online version contains supplementary material available at https://doi. org/10.1186/s12909-022-03186-0.

\section{Additional file 1.}

\section{Acknowledgements}

The authors would like to thank the faculties who assisted with the data collection for this questionnaire in Tongji Medical College. The authors would also like to thank the participants for taking time to complete the questionnaire. Besides, we would like to thank WenJuanXing for providing us with such a platform to complete the questionnaire survey.

\section{Authors' contributions}

$J-Y Z$ designed, analyzed and contributed in collecting the data, interpreting the results, and writing the draft manuscript. Y-JL contributed in collecting the data, interpreting the results. Z-CF contributed in guiding research design and revising the manuscript. TS and MX contributed in collecting and organizing the data. All authors read and approved the final manuscript.

\section{Funding}

This work was supported by the Double First Class International Cooperation Project (Grant No. 5001516037) and Huazhong University of Science and Technology Teaching Research Project (Grant No. 2019051).

\section{Availability of data and materials}

The datasets used and/or analysed during the current study are in Chinese and are available from the corresponding author on reasonable request but will require translation to English.

\section{Declarations}

\section{Ethics approval and consent to participate}

The study was approved by the ethical board of Tongji Medical College. Participation was voluntary, anonymity was guaranteed. No individual data were collected and informed consent was obtained. All methods were carried out in accordance with relevant guidelines and regulations.

\section{Consent for publication}

Not applicable.

\section{Competing interests}

We declare no competing interests.

Received: 25 August 2021 Accepted: 14 February 2022

Published online: 25 February 2022

\section{References}

1. Zimmerman BJ. A social cognitive view of self-regulated academic learning. J Educ Psychol. 1989;81(3):329-39. https://doi.org/10.1037/00220663.81.3.329.

2. Durning SJ, Cleary TJ, Sandars J, Hemmer P, Kokotailo P, Artino AR. Perspective: viewing "strugglers" through a different lens: how a self-regulated learning perspective can help medical educators with assessment and remediation. Acad Med. 2011;86(4):488-95. https://doi.org/10.1097/ ACM.0b013e31820dc384.

3. Sandars J, Cleary TJ. Self-regulation theory: applications to medical education: AMEE guide no. 58. Medical Teach. 2011;33(11):875-86. https:// doi.org/10.3109/0142159x.2011.595434.

4. Boekaerts M. Self-regulated learning: a new concept embraced by researchers, policy makers, educators, teachers, and students. Learn Instr. 1997;7(2):161-86. https://doi.org/10.1016/S0959-4752(96)00015-1.

5. Brydges R, Butler D. A reflective analysis of medical education research on self-regulation in learning and practice. Med Educ. 2012;46(1):71-9. https://doi.org/10.1111/j.1365-2923.2011.04100.x.

6. Van Houten-Schat MA, Berkhout JJ, van Dijk N, Endedijk MD, Jaarsma ADC, Diemers AD. Self-regulated learning in the clinical context: a systematic review. Med Educ. 2018;52(10):1008-15. https://doi.org/10.1111/ medu.13615.

7. Berkhout JJ, Helmich E, Teunissen PW, Van den Berg JW, Van der Vleuten $C P$, Jaarsma ADC. Exploring the factors influencing clinical students' selfregulated learning. Med Educ. 2015;49(6):589-600.

8. Sitzmann T, Ely K. A meta-analysis of self-regulated learning in workrelated training and educational attainment: what we know and where we need to go. Psychol Bull. 2011;137(3):421-42.

9. Guo FSH, Zhang LR, et al. Inlfuencing factors of college Students' autonomous learning in newly established universities. China Educ Technol Equip. 2018;20:87-9. https://doi.org/10.3969/j.issn.1671-489X.2018.20. 087.

10. YG Z. The study on the relations among the self-regulated learning, achievement goal orientation and academic achievement of college students: Master. Anhui Normal University; 2007. https://doi.org/10.7666/d. D513302.

11. DF W. Study on self-directed learning ability and its influencing factors among nursing undergraduates: Master. Central South University; 2014.

12. Chai JJZH, Liu JH, et al. Analysis of the ability and affected factors on selfregulated learning in 8-year program medical students at Peking union medical college. Basic Clin Med. 2019;39(005):763-8. https://doi.org/10. 3969/j.issn.1001-6325.2019.05.031.

13. Lockspeiser TM, Li ST, Burke AE, Rosenberg AA, Dunbar AE 3rd, Gifford KA, et al. In pursuit of meaningful use of learning goals in residency: a qualitative study of pediatric residents. Acad Med. 2016;91(6):839-46. https:// doi.org/10.1097/acm.0000000000001015.

14. Li ST, Tancredi DJ, Co JP, West DC. Factors associated with successful self-directed learning using individualized learning plans during pediatric residency. Acad Pediatr. 2010;10(2):124-30. https://doi.org/10.1016/j.acap. 2009.12.007.

15. Alegría DA, Boscardin C, Poncelet A, Mayfield C, Wamsley M. Using tablets to support self-regulated learning in a longitudinal integrated clerkship. Med Educ Online. 2014;19:23638. https://doi.org/10.3402/meo.v19.23638.

16. Berkhout JJ, Helmich E, Teunissen PW, van der Vleuten CP, Jaarsma AD How clinical medical students perceive others to influence their selfregulated learning. Med Educ. 2017;51(3):269-79. https://doi.org/10. 1111/medu.13131.

17. White CB. Smoothing out transitions: how pedagogy influences medical students' achievement of self-regulated learning goals. Adv Health 
Sci Educ Theory Pract. 2007;12(3):279-97. https://doi.org/10.1007/ s10459-006-9000-z.

18. Laura, Nota, and, Salvatore, Soresi, and, Zimmerman, Barry J.: Self-regulation and academic achievement and resilience: a longitudinal study. Int J Educ Res 2004 41(3):198-215.

19. Zhou YGSQ, Ge MG. A study on the relations of college Students' selfregulated learning and achievement goal orientation with academic achievement. J Psychol Sci. 2010;33(1):194-7. https://doi.org/10.16719/j. cnki.1671-6981.2010.01.066.

20. Sahranavard S, Miri MR, Salehiniya H. The relationship between selfregulation and educational performance in students. J Educ Health Promot. 2018;7:154. https://doi.org/10.4103/jehp.jehp_93_18.

21. Sobral DT. What kind of motivation drives medical students'learning quests? Med Educ. 2004;38(9):950-7. https://doi.org/10.1111/j.1365-2929. 2004.01913.x

22. Turan S, Konan A. Self-regulated learning strategies used in surgical clerkship and the relationship with clinical achievement. J Surg Educ. 2012;69(2):218-25. https://doi.org/10.1016/j.jsurg.2011.09.003.

23. Lucieer SM, Jonker L, Visscher C, Rikers RM, Themmen AP. Self-regulated learning and academic performance in medical education. Med Teach. 2016;38(6):585-93. https://doi.org/10.3109/0142159x.2015.1073240.

24. Sandars J. The use of reflection in medical education: AMEE guide no. 44. Med Teach. 2009;31(8):685-95. https://doi.org/10.1080/0142159090 3050374.

25. TW. A study on the influence of family capital on academic achievement of college students: Master. Jiangxi Normal University; 2020. https://doi. org/10.27178/d.cnki.gjxsu.2020.001387.

26. Zhu ZDWJ, Zhang W, et al. Constraction of self-regulated learning scale for college students. Psychol Dev Educ. 2005;21(3):60-5. https://doi.org/ 10.3969/j.issn.1001-4918.2005.03.012.

27. Team RC. R: a language and environment for statistical computing; 2013. https://doi.org/10.1890/0012-9658(2002)083[3097:CFHIWS]2.0.CO;2.

28. Norman GR SD. Biostatistics: the bare essentials. 3rd ed. 3rd ed. Shelton: People's Medical Publishing House; 2008.

29. Zimmerman BJ, Boekarts M, Pintrich PR, Zeidner M. A social cognitive perspective; 2000.

30. Zumbrunn S, Tadlock J, Roberts E. Encouraging self-regulated learning in the classroom: a review of the literature; 2011.

31. Wen HMJ, Zhu YX, et al. The application of peer-assisted learning in medical education. Chinese J Med Educ. 2018;2:232-6. https://doi.org/10 3760/cma.j.issn.1673-677X.2018.02.015.

32. Bandura A. Social foundations of thought and action: a social cognitive theory. J Appl Psychol. 1986;12(1):169. https://doi.org/10.2307/258004.

33. Herrmann-Werner A, Gramer R, Erschens R, Nikendei C, Wosnik A, Griewatz J, et al. Peer-assisted learning (PAL) in undergraduate medical education: an overview. Z Evid Fortbil Qual Gesundheitswes. 2017;121:74-81. https://doi.org/10.1016/j.zefq.2017.01.001.

34. Pizzimenti MA, Axelson RD. Assessing student engagement and selfregulated learning in a medical gross anatomy course. Anat Sci Educ. 2015;8(2):104-10. https://doi.org/10.1002/ase.1463.

35. Cook D, Thompson WG, Thomas KG. The motivated strategies for learning questionnaire: score validity among medicine residents. Med Educ. 2011;45(12):1230-40. https://doi.org/10.1111/j.1365-2923.2011.04077.x.

36. Stegers-Jager KM, Cohen-Schotanus J, Themmen A. Motivation, learning strategies, participation and medical school performance. Med Educ. 2012;46(7). https://doi.org/10.1111/j.1365-2923.2012.04284.x.

\section{Publisher's Note}

Springer Nature remains neutral with regard to jurisdictional claims in published maps and institutional affiliations.

Ready to submit your research? Choose BMC and benefit from:

- fast, convenient online submission

- thorough peer review by experienced researchers in your field

- rapid publication on acceptance

- support for research data, including large and complex data types

- gold Open Access which fosters wider collaboration and increased citations

- maximum visibility for your research: over $100 \mathrm{M}$ website views per year

At BMC, research is always in progress.

Learn more biomedcentral.com/submissions 